\title{
Statistical Modeling and Kinetic Studies on the Adsorption of Reactive Red 2 by a Low-Cost Adsorbent: Grape Waste-Based Activated Carbon Using Sulfuric Acid Activator-Assisted Thermal Activation
}

\author{
Seyyed Alireza Mousavi $\mathbb{D}^{1}{ }^{1}$ Davood Shahbazi $\mathbb{D}^{1,}{ }^{1,2}$ Arezoo Mahmoudi $\mathbb{D}^{\mathbb{1}}{ }^{1}$ \\ Parviz Mohammadi $\mathbb{D}^{1}$ and Tooraj Massahi $\mathbb{D}^{2}$ \\ ${ }^{1}$ Department of Environmental Health Engineering, And Research Center for Environmental Determinants of Health (RCEDH), \\ School of Public Health, Kermanshah University of Medical Sciences, Kermanshah, Iran \\ ${ }^{2}$ Students Research Committee, Kermanshah University of Medical Sciences, Kermanshah, Iran
}

Correspondence should be addressed to Seyyed Alireza Mousavi; seyyedalirezamousavi@gmail.com

Received 10 April 2021; Accepted 25 October 2021; Published 28 November 2021

Academic Editor: George Kyzas

Copyright (C) 2021 Seyyed Alireza Mousavi et al. This is an open access article distributed under the Creative Commons Attribution License, which permits unrestricted use, distribution, and reproduction in any medium, provided the original work is properly cited.

\begin{abstract}
The efficiency of activated carbon produced from grape waste as a low-cost, nontoxic, and available adsorbent to remove Reactive Red 2 from aqueous solution has been investigated. The prepared activated carbon has been characterized by FTIR, SEM, and BET. The results of characterization indicate the successful conversion of grape waste into mesoporous AC with desirable surface area consist of different functional groups. The results of statistical modeling displayed high $R^{2}$ value of $0.97 \%$ for dye removal that shows the developed model has acceptable accuracy. The effect of independent variables indicated that the highest adsorption (96.83\%) obtained at $\mathrm{pH} 3$, adsorbent dosage of $12.25 \mathrm{~g} / \mathrm{L}$, and initial dye concentration of $100 \mathrm{mg} / \mathrm{L}$ when the adsorption time was $90 \mathrm{~min}$. The results of isotherms modeling showed that the data fit well with the Langmuir (type II). The kinetic studies using pseudofirst-order and pseudosecond-order models pointed out that the type (I) of pseudosecondorder kinetic model provided the best fit to the adsorption data. Parameters of thermodynamics including Gibbs energy $\left(\Delta G^{\circ}\right)$ and $k_{\mathrm{o}}$ were calculated. The values of $\Delta G^{\circ}$ indicated that the dye adsorption of RR2 is spontaneous. The agricultural wastes due to special points such as low-cost, availability, and high ability to produce an adsorbent with high efficiency to remove dye can be proposed for water and wastewater treatment.
\end{abstract}

\section{Introduction}

In recent years, the use of synthetic dyes in industries has increased dramatically due to low-cost in synthesis, efficient synthesis process, high stability and resistance to temperature, light and detergent, and other factors in comparison to natural dyes $[1,2]$. Synthetic dyes are widely used in different industries such as paper, textile, food, plastic, leather, and cosmetic $[3,4]$. The presence of organic dyes in the environment, even in low concentrations, can threaten human health and cause diseases such as gastritis, heinz body formation, skin allergies, tissue necrosis, and cancer [5]. Dyes can be divided into different types, namely, reactive, acidic, direct, cationic, disperse, and vat according to their characteristics and application [6]. Reactive dyes due to their stability, high solubility, high dye variety, and low-cost are one of the most common used synthetic dyes which are widely used to dye cotton and other cellulosic fibers, nylon, and wool [7, 8].

Reactive Red 2 (RR2) is a reactive azo dye and is difficult to be decomposed in natural environment due to its strong covalent bonds [9]. Direct discharge of colored wastewater from aforementioned industries into the environment leads 
to serious environmental problems [10]. Therefore, various methods such as biological, chemical, and physical methods or a combination of these methods are used to treat wastewater containing dyes and thus reduce the environmental hazards of dyes [11]. Researchers has used a variety of methods, such as coagulation [12], ozonation [13], Fenton processes [14], biodegradation [15], photodegradation [16], and adsorption [17] to remove dyes from water and wastewater efficiently. The results of previous research works made clear that dyes cannot be degraded effectively by chemical and biological processes [18].

Nowadays, adsorption due to its high efficiency, high selectivity at molecular level, low energy consumption, easy operation, and the ability to separate different chemical compound has been used widely for dye removal [19]. Adsorption is a physicochemical method in which the soluble molecule (such as dye molecules) is attached to an adsorbent surface according to its physical and chemical properties. Depending on the properties of the adsorbent and the type of dyes, different interactions may occur between the adsorbent and the dye such as electrostatic interaction or Van der Waals forces [20]. Thus, adsorption is an effective and economical efficient and method with high potential for removing dyes from aquatic environments. Among the large number of adsorbents, activated carbon (AC) is widely used due to high surface area, microporous structure, and high adsorption capacity [21, 22].

The commercial AC is expensive and therefore, many studies have been carried out to produce AC from low-cost raw materials. Agricultural wastes are a good option for producing $\mathrm{AC}$, which is less expensive and environmentally friendly. In the last several decades, different agricultural wastes have been used as low-cost adsorbent, such as peanuts [23], apricots stones wastes [24], grape stalk [25], olive almonds [26] and cherries [27]. Agricultural waste is made from hemicellulose, cellulose, and other functional groups that are a suitable alternative to commercial activated carbon. Agricultural waste is cheap and abundantly available and sometimes even causes a lot of environmental problems [28]. Therefore, converting agricultural wastes into valuable materials such as AC is valuable in points of economic and environmental protection view [29]. For this purpose, grape waste was used to prepare activated carbon. Grapes are one of the most common fruit products in the world. Approximately 7.5 million of land around the world in 2017 is under grapevine cultivation [30]. Therefore, pruning the branches of vines to produce higher quality grapes produces a significant amount of agricultural wastes. Using grape wood to make adsorbent is an efficient management strategy to control agricultural wastes.

This study is aimed at investigating the Reactive Red 2 (RR2) removal using prepared activated carbon from grape wood wastes as low-cost adsorbent from aqueous solution. The effects of contact time, initial dye concentration, adsorbent dosage, and solution $\mathrm{pH}$ on the $\mathrm{RR} 2$ adsorption rate have been modeled and optimized using the central composite designs (CCD) through response surface methodology (RSM). The mechanism of adsorption has been described through isotherm and kinetic studies.

\section{Materials and Methods}

2.1. Chemicals and Reagents. All chemicals such as RR2 $\left(\mathrm{C}_{19} \mathrm{H}_{10} \mathrm{Cl}_{2} \mathrm{~N}_{6} \mathrm{Na}_{2} \mathrm{O}_{7} \mathrm{~S}_{2}\right)$, sulfuric acid, and $\mathrm{NaOH}$ used in this study were reagent grade. The RR2 with purity of $98 \%$ has been provided by Merck Company, Germany. The chemical activation of adsorbent carried out by using $98 \%$ sulfuric acid. The $\mathrm{pH}$ of solution was adjusted using $\mathrm{NaOH}$ $\left(1 \mathrm{~mol} \mathrm{~L}^{-1}\right)$ and $\mathrm{HCl}\left(1 \mathrm{~mol} \mathrm{~L}^{-1}\right)$, which were purchased from Merck company. The chemical structure of RR2 dye is offered in Figure 1 [31].

2.2. Activated Carbon Preparation. Grape wood waste was obtained from the Kermanshah rural area in the western region of Iran. The raw material was crushed mechanically and transferred to the laboratory. In order to eliminate impurities such as debris and dust, grape wood waste cleaned and washed with distilled water and dried at $100^{\circ} \mathrm{C}$ for $3 \mathrm{~h}$. The activation agent sulfuric acid (with 98\% purity) was used for the chemical preparation of activated carbon during $8 \mathrm{~h}$ with the weight ratio of $1: 10$ for sulfuric acid to grape wood wastes. Then, it was dried for $24 \mathrm{~h}$ at $100^{\circ} \mathrm{C}$. In next phase, the thermal activation carried out by oven at $750^{\circ} \mathrm{C}$ for 1 hour. After cooling, the AC was passed through the sieve mesh size 50 . The powder has been neutralized with $\mathrm{NaOH}$ and $\mathrm{HCl}$. Finally, grape wood activated carbon (GWAC) was dried at $100^{\circ} \mathrm{C}$ for $3 \mathrm{~h}$.

2.3. Characterization of Activated Carbon. To study the physical and chemical characteristics of GWAC, Fourier transform infrared (FTIR), scanning electron microscopy (SEM), and Brunauer-Emmett-Teller (BET) have been used. The surface morphology of the adsorbent was observed with SEM (Jeol JSM 840A, Japan). The BET has been used to analysis the specific surface area of GWAC. The FTIR has been used to determine functional groups of adsorbent.

2.4. Experimental Design and Empirical Modeling. In this study, Design-Expert software (version 11) was applied for the design of experiments and data analysis through RSM using CCD technique. Response surface methodology is a statistical method that uses the quantitative data from experiments to examine the interaction of the several parameters affecting the process and study the responses of various factors by varying them simultaneously $[32,33]$. The effects of four independent variables, such as contact time (A), initial $\mathrm{pH}(\mathrm{B})$, adsorbent dosage (C), and initial dye concentration (D), were investigated by means of (3-level-4-factor) CCD. The effect of input factors on the responses was investigated by analysis of variance (ANOVA) through statistical evaluation of $P$ value and $F$ value of regression coefficients $(P<0.05)$. In addition, the validity of the model was reported in terms of the coefficient of determination $\left(R^{2}\right)$, adjusted coefficient of determination $\left(R^{2}\right.$ adj.), and sufficient accuracy (AP). Finally, the three-dimensional response level diagrams have been developed to show the interrelationship between independent factors and their related effects on the response. For each parameter, the ranges and levels are given in Table 1. With the suggestion of the software, the 
<smiles>O=[N+]([O-])c1cc(N=Nc2ccccc2)c(O)c(Nc2nc(Cl)nc(Cl)n2)c1</smiles>

FIgURE 1: The structural formula for RR2.

TABLE 1: Ranges and level of studied parameters in order to design the experiments.

\begin{tabular}{lcccc}
\hline Parameter name & Unit & Symbols & Low & High \\
\hline Contact time & Min & $\mathrm{A}$ & 10 & 90 \\
$\mathrm{pH}$ & - & $\mathrm{B}$ & 3 & 11 \\
Adsorbent dosage & $\mathrm{g}$ & $\mathrm{C}$ & 0.25 & 12.25 \\
Initial concentration & $\mathrm{Mg} / \mathrm{L}$ & $\mathrm{D}$ & 100 & 500 \\
\hline
\end{tabular}

experiments were carried out at 78 runs (with three repetitions). The average of each run, except for the 6 central run, is presented in Table 2 . The quadratic equation model (Eq. (1)), which includes all interaction terms, was used to calculate the predicted response.

$$
Y=\beta_{0}+\sum_{i=1}^{k} \beta_{i} X_{i}+\sum_{i=1}^{k} \beta_{i i} X_{i}^{2}+\sum_{i=1}^{k-1} \sum_{j=2}^{k} \beta_{i j} x_{i} x_{j}+e
$$

The quadratic model based on Eq. (1) was applied to evaluate the coefficients of the statistical model, where $Y$ is the response, $\beta \mathrm{o}$ is the constant coefficient, $\beta i$ is the linear coefficients, $\beta i j$ is the interaction coefficients, $\beta i i$ is the quadratic coefficients, $x_{i}$ and $x_{j}$ are the coded values of the investigated variables, and $e$ is the statistical error term.

2.5. Batch Equilibrium Studies. This empirical study carried out at a laboratory bench scale by using activated carbon prepared from grape wood waste for removing RR2 from aqueous solution. In the first phase, a series of batch experiments were performed to investigate the removal of RR2 dye from synthetic wastewater. The adsorption process has been conducted at the different values of independent variables; contact time (10 to $90 \mathrm{~min}$ ), $\mathrm{pH}$ (3-11), initial concentration of dye $(100-500 \mathrm{mg} / \mathrm{L})$, and adsorption dosage $(0.25$ to $12.25 \mathrm{~g} / \mathrm{L}$ ) using a series of pyrex glass with total volume of $250 \mathrm{~mL}$ and working volume of $100 \mathrm{~mL}$. Ambient temperature and mixing speed were constant during process at 25 $\pm 1^{\circ} \mathrm{C}$ and $100 \mathrm{rpm}$, respectively. To carry out the experiments, the initial $\mathrm{pH}$ of dye solution was adjusted using $\mathrm{NaOH}$ or $\mathrm{HCl}$. The residual concentration of dye was determined by measuring its absorbance in a UV-Visible spectrophotometer (Jenway 6305, Germany Model) at the maximum wavelength of $665 \mathrm{~nm}$ after centrifuge (Shimi fan, Iran) of sample at $3800 \mathrm{rpm}$ for $7 \mathrm{~min}$. The amount of adsorbed dye and RR2 removal efficiency (\%) were calculated by following equations (Eqs. (2) and (3)) [34]. The rep-
TABLE 2: Experimental conditions for adsorption process in the presence of prepared GWAC.

\begin{tabular}{|c|c|c|c|c|c|}
\hline $\begin{array}{l}\text { Run } \\
\text { no. }\end{array}$ & $\begin{array}{l}\text { Contact } \\
\text { time }\end{array}$ & $\mathrm{pH}$ & $\begin{array}{c}\text { Parameters } \\
\text { Adsorbent } \\
\text { dosage }\end{array}$ & $\begin{array}{c}\text { Dye } \\
\text { concentration }\end{array}$ & $\begin{array}{c}\text { Response } \\
\text { Removal } \\
(\%)\end{array}$ \\
\hline$\overline{1}$ & 10 & 11 & 12.25 & 100 & 38.9 \\
\hline 2 & 90 & 3 & 12.25 & 100 & 96.83 \\
\hline 3 & 10 & 3 & 12.25 & 500 & 9.8 \\
\hline 4 & 50 & 7 & 3.25 & 300 & 70.6 \\
\hline 5 & 10 & 3 & 0.25 & 500 & 2 \\
\hline 6 & 90 & 3 & 12.25 & 500 & 63.4 \\
\hline 7 & 10 & 3 & 0.25 & 100 & 25 \\
\hline 8 & 90 & 11 & 0.25 & 100 & 33.66 \\
\hline 9 & 50 & 7 & 6.25 & 400 & 67.9 \\
\hline 10 & 90 & 3 & 0.25 & 500 & 1.33 \\
\hline 11 & 10 & 11 & 12.25 & 500 & 11.6 \\
\hline 12 & 50 & 9 & 6.25 & 300 & 81.06 \\
\hline 13 & 50 & 5 & 6.25 & 300 & 89 \\
\hline 14 & 90 & 11 & 0.25 & 500 & 1.73 \\
\hline 15 & 50 & 7 & 6.25 & 200 & 80 \\
\hline 16 & 30 & 7 & 6.25 & 300 & 78.96 \\
\hline 17 & 10 & 11 & 0.25 & 100 & 22 \\
\hline 19 & 90 & 11 & 12.25 & 500 & 61.33 \\
\hline 19 & 10 & 11 & 0.25 & 500 & 0.53 \\
\hline 20 & 50 & 7 & 9.25 & 300 & 85.53 \\
\hline 21 & 70 & 7 & 6.25 & 300 & 89.53 \\
\hline 22 & 90 & 3 & 0.25 & 100 & 37.66 \\
\hline 23 & 10 & 3 & 12.25 & 100 & 41 \\
\hline 24 & 90 & 11 & 12.25 & 100 & 93.5 \\
\hline 25 & 50 & 7 & 6.25 & 300 & 52.6 \\
\hline 26 & 50 & 7 & 6.25 & 300 & 85 \\
\hline 27 & 50 & 7 & 6.25 & 300 & 85.3 \\
\hline 28 & 50 & 7 & 6.25 & 300 & 84.3 \\
\hline 29 & 50 & 7 & 6.25 & 300 & 83.6 \\
\hline 30 & 50 & 7 & 6.25 & 300 & 84.4 \\
\hline
\end{tabular}

etition of analysis was considered when an error higher than $5 \%$ was observed in the samples during the test.

$$
\begin{gathered}
\mathrm{qe}=\frac{\left(C_{0-} C_{e}\right)}{w} \times v, \\
\% R=\frac{C_{0-} C_{e}}{C_{0}} \times 100,
\end{gathered}
$$

where $C_{0}$ and $C_{e}$ are the initial and final dye concentrations $(\mathrm{mg} / \mathrm{L})$, respectively, $q_{e}$ is the amount of adsorbate per mass of the adsorbent $(\mathrm{mg} / \mathrm{g}), V$ is the volume of solution $(\mathrm{L})$, and $W$ is the mass of adsorbent $(\mathrm{g})$ [35]. 

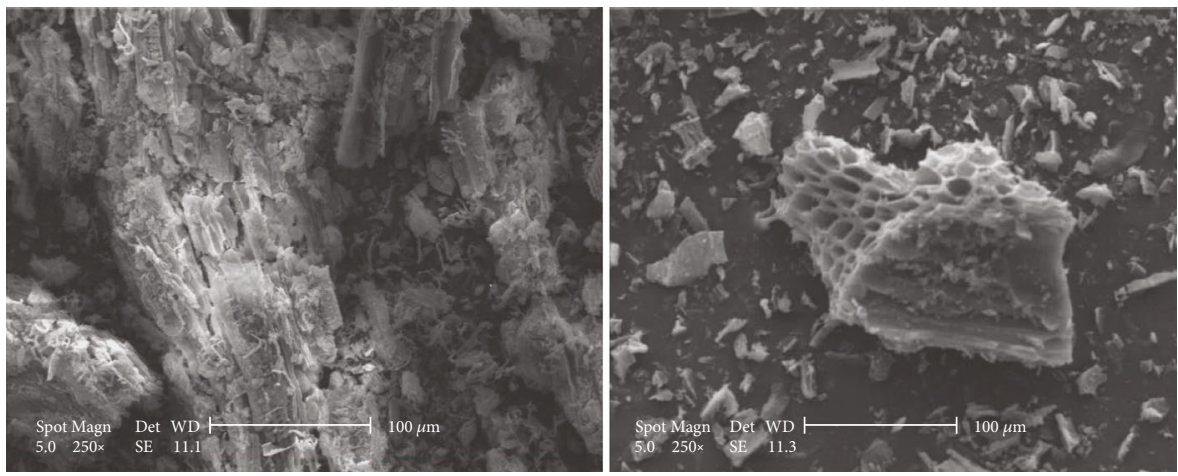

Figure 2: SEM image of prepared AC.

\section{Results and Discussions}

3.1. Characteristics of Adsorbent. The SEM image (Figure 2) indicates the surface porosity of GWAC. According to Figure 2, presence of honeycomb pores on the GWAC surface makes clear that adsorbent has ability to remove dye from aqueous solution by adsorption process. Previous studies reported that high porosity increases the surface area and effectively increases the adsorption efficiency [36]. Based on BET analysis, the adsorbent-specific surface area was $119.084 \mathrm{~m}^{2} / \mathrm{g}$.

The FT-IR spectrum is very important for determining the characteristics of the functional groups as well as their changes in the adsorbent. The FT-IR spectra of the adsorbent after RR2 adsorption are shown in Figure 3. Based on various studies, the peaks of the Figure represent between 1000 and $1200 \mathrm{~cm}^{-1}$ are related to the C-O functional group. The band at 3200 to $3600 \mathrm{~cm}^{-1}$ corresponds to the $\mathrm{O}-\mathrm{H}$ tensile vibration of the hydroxyl functional groups. The peak at 1700 to $1800 \mathrm{~cm}^{-1}$ is related to the $\mathrm{C}=\mathrm{O}$ stretch of the carboxyl groups. The peak at about $960 \mathrm{~cm}^{-1}$ may be due to the vibration of the $\mathrm{C}-\mathrm{C}$ or $\mathrm{C}-\mathrm{H}$ groups [37].

3.2. Statistical Analysis and Modeling. The results of analysis of variance (ANOVA) have been summarized in Table 3. Based on the results adsorbent dosage, initial concentration of dye and contact time has a positive effect on adsorption efficiency. The positive amount of variables indicates the effect of variables, while the negative value indicates an inverse relationship between the factors and their response. $R^{2}$ and $R_{\text {adj. }}^{2}$ for dye removal are 0.9797 and 0.9751 , respectively, which confirms that there is a good match between predicted data and experimental data. The model $F$ value 216.67 indicates that the model was significant for RR2 removal. Values of Prob $>F$ less than 0.05 mean that the model terms were significant, while values greater than 0.05 indicate that the model terms are not significant. The lack of fit value 0.4925 is not significant and confirms that the model is adequate. Adequate precision measured the signal to noise ratio that a value of this parameter greater than 4 is generally essential $[38,39]$. In this work, obtained adequate precision was 42 for the degradation of RR2 that con-

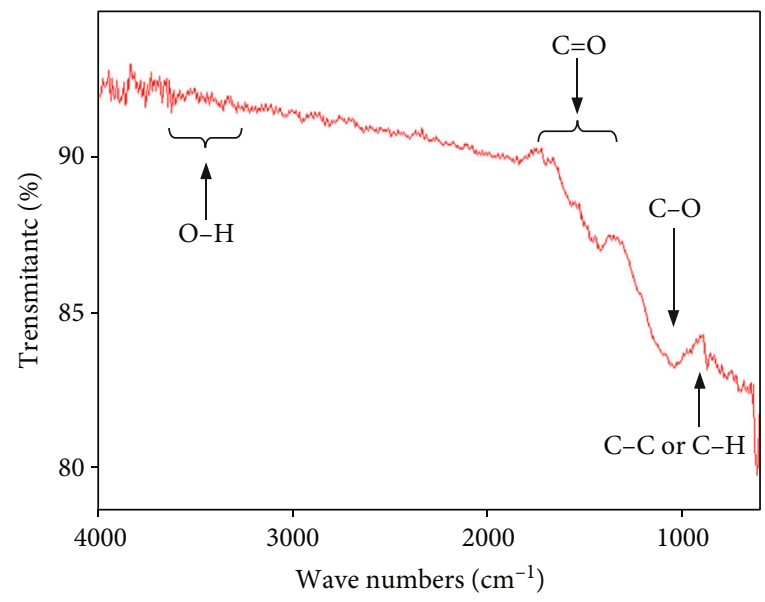

FIGURE 3: FTIR spectrum after adsorption.

firmed an adequate signal; thus, obtained model in this work could be used to navigate the design space (Eq. (4)).

$$
\begin{aligned}
\text { Removal }= & +82.50+14.84 A-1.14 B+18.11 C-14.66 D \\
& -0.2021 \mathrm{AB}+11.87 \mathrm{AC}-1.99 \mathrm{AD}+0.0854 \mathrm{BC} \\
& +0.7563 \mathrm{BD}-0.6479 \mathrm{CD}+3.46 \mathrm{~A}^{2}+6.59 B^{2} \\
& -21.08 C^{2}-37.74 D^{2} .
\end{aligned}
$$

3.3. Effects of Variables and Comparison. The 3D surface response and contour plot of the quadratic model have been developed by the Design Expert software version 8, and they used to study the interactive relationships between independent variables and response.

3.3.1. Effect of Initial $\mathrm{pH}$ and Contact Time. The $\mathrm{pH}$ has a large effect on the adsorption capacity of the adsorbent. The $\mathrm{pH}$ can affected on the electrical charge of adsorbent surface, dissociation of various functional groups on the active sites of the adsorbent, and the ionic forms of adsorbate molecule. Therefore, it can play an important role in the dye adsorption process [40]. Figure 4 shows the interaction effects of contact time and initial $\mathrm{pH}$ based on response in the adsorption process. In order to study the effect of $\mathrm{pH}$ on dye removal efficiency, different initial values of $\mathrm{pH}(3,5$, 
TABle 3: Statistical parameters and ANOVA results using Design-Expert 11.0.0 for the studied variables.

\begin{tabular}{|c|c|c|c|c|c|c|}
\hline Source & Sum of squares & Df & Mean square & $F$ value & $P$ value & \\
\hline Model & 85022.46 & 14 & 6073.03 & 216.67 & $<0.0001$ & Significant \\
\hline$A$ & 10906.21 & 1 & 10906.21 & 389.11 & $<0.0001$ & Significant \\
\hline$B$ & 63.81 & 1 & 63.81 & 2.28 & 0.1363 & \\
\hline C & 16238.42 & 1 & 16238.42 & 579.35 & $<0.0001$ & Significant \\
\hline$D$ & 10637.74 & 1 & 10637.74 & 379.53 & $<0.0001$ & Significant \\
\hline $\mathrm{AB}$ & 1.96 & 1 & 1.96 & 0.0699 & 0.7923 & \\
\hline $\mathrm{AC}$ & 6761.63 & 1 & 6761.63 & 241.24 & $<0.0001$ & Significant \\
\hline $\mathrm{AD}$ & 190.80 & 1 & 190.80 & 6.81 & 0.0113 & \\
\hline $\mathrm{BC}$ & 0.3502 & 1 & 0.3502 & 0.0125 & 0.9114 & \\
\hline $\mathrm{BD}$ & 27.45 & 1 & 27.45 & 0.9794 & 0.3261 & \\
\hline $\mathrm{CD}$ & 20.15 & 1 & 20.15 & 0.7189 & 0.3997 & \\
\hline$A^{2}$ & 5.97 & 1 & 5.97 & 0.2128 & 0.6461 & \\
\hline$B^{2}$ & 21.68 & 1 & 21.68 & 0.7734 & 0.3825 & \\
\hline$C^{2}$ & 221.68 & 1 & 221.68 & 7.91 & 0.0066 & \\
\hline$D^{2}$ & 710.92 & 1 & 710.92 & 25.36 & $<0.0001$ & Significant \\
\hline Residual & 1765.81 & 63 & 28.03 & & & \\
\hline Lack of fit & 269.62 & 10 & 26.96 & 0.9551 & & \\
\hline Pure error & 1496.19 & 53 & 28.23 & 0.4925 & & \\
\hline Cor total & 86788.27 & 77 & & & & \\
\hline
\end{tabular}

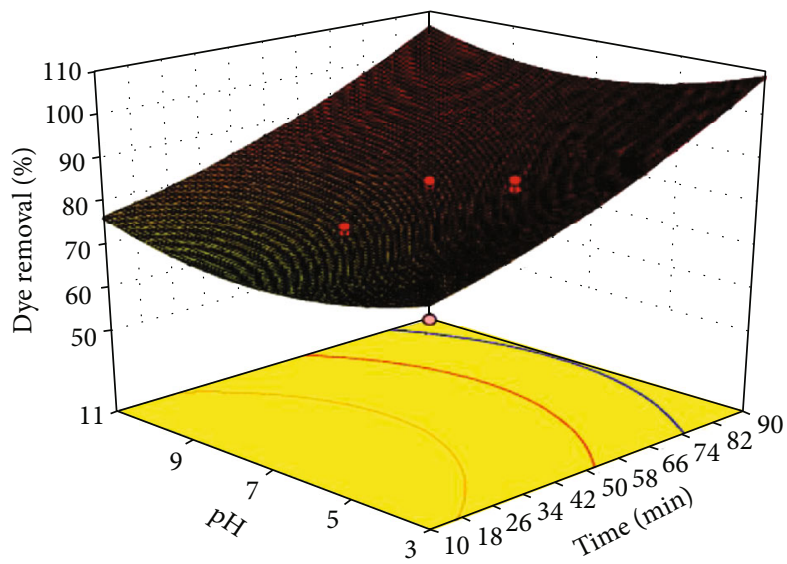

(a)

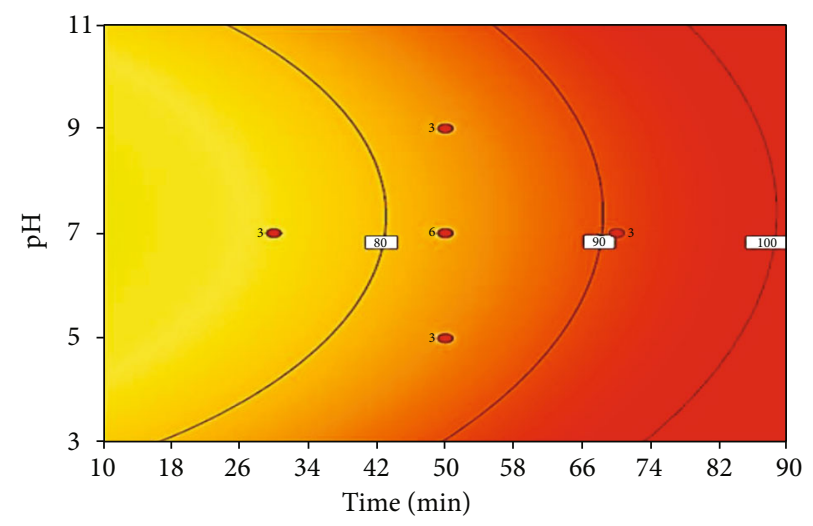

(b)

Figure 4: 3D response surface and 2D contour plots show the effect of $\mathrm{pH}$ and contact time on the RR2 removal.

7, 9, and 11) were examined. As shown in Figure 4, the dye removal efficiency increased by increasing of $\mathrm{pH}$ from 3 to 7 , but it decreased by increasing of $\mathrm{pH}$ from 7 to 11 . It is evident that both variables ( $\mathrm{pH}$ and time) have a strong influence on the RR2 removal [41]. The adsorption of RR2 was high at low $\mathrm{pH}$ when $\mathrm{pH}<\mathrm{pH}_{\mathrm{ZPC}}$ (6.7) in this condition, and the adsorbent surface gets a positive charge. The study by Nirmaladevi (2020) confirmed the results of this study [42]. The results of study bySenthilkumaar et al. (2006) showed that the removal of reactive red dye is greater at low $\mathrm{pH}$ [43]. At acidic conditions, binding sites of the adsorbent would be closely associated with the hydrogen ions which act as bridging ligands between the adsorbent surface and the dye molecule [44]. A comparison between the results of present study and others studies is presented in Table 4. As can be seen, the amount of RR2 removal at acidic $\mathrm{pH}$ has been reported more than other values. In addition, the dye removal obtained in this study has been reported at an acceptable level compared to other adsorbents. Consequently, activated carbon made from grape wood waste is an efficient adsorbent for RR2 dye removal from aqueous solution.

One of the most important design parameters of adsorption studies is the contact time between the dye and the adsorbent [45]. The results show that with increasing contact time from 10 to 90 minutes, the percentage of dye 
TABLE 4: The comparison of results of this study with previous works.

\begin{tabular}{lcccccc}
\hline Removal (\%) & Contact time $(\mathrm{min})$ & Initial Co. RR2 $(\mathrm{mg} / \mathrm{L})$ & $\mathrm{pH}$ & Adsorbent $(\mathrm{g} / \mathrm{L})$ & Adsorbent & Reference \\
\hline 96.83 & 90 & 100 & 3 & 12.25 & Grape waste & Hazelnut shells \\
$70>$ & 30 & 20 & 3 & 0.2 & Present study \\
$49.91^{*}$ & - & 120 & 2 & 2 & Soya bean meal & {$[50]$} \\
$95>$ & 25 & 220 & 2 & 0.3 & Clay montmorillonite & {$[54]$} \\
98 & 100 & 60 & 2 & 0.05 & Leucophloea wood sawdust & {$[42]$} \\
$90>$ & 40 & - & 2 & 1 & Dried fungal & {$[51]$} \\
\hline
\end{tabular}

${ }^{*}$ Maximum uptake capacity.

removal increases. Initially, the adsorption process decreases rapidly and gradually over time due to the presence of voids on the activated carbon surface. It means at first, there are more sites for adsorption, which with the passage of time and the occupation of adsorbent sites, that the carbon adsorption capacity reaches a constant amount and the socalled equilibrium between the amount of adsorbed dye and the amount of desorption. Therefore, the amount of adsorption is also reduced [46]. Bazrafshan et al. (2013) conducted a study on the removal of Reactive Red 120 using carbon made from cumin herb wastes. The results of this study show that increasing the contact time has a positive effect on the dye removal process [47].

3.3.2. Effect of Adsorbent Dosage and Dye Concentration. The adsorbent concentration is an important factor because it determines the capacity of the adsorbent for a given initial RR2 concentration. In order to determine the effect of adsorbent dosage on the adsorption process, 0.25 to $12.25 \mathrm{~g} / \mathrm{L}$ adsorbent (activated carbon obtained from grape wood wastes) was used for adsorption experiments. Figure 5 shows the interaction effects of dye concentration and adsorbent dosage in the response process. As shown in Figure 5, with increasing of adsorbent dosage up to reach to equilibrium in high dosages, the RR2 removal efficiency increases. The highest adsorption rate was obtained in $12.25 \mathrm{~g} / \mathrm{L}$ of activated carbon that was $96.83 \%$. This is due to the fact that as the adsorbent dosage is increased, the surface area available for adsorption increases, thus producing more active sites for adsorption [48, 49]. The comparison of the results of current study with previous research works indicated same effects of different variables (Table 4). The results of Al-Sharify et al. (2013) study show, with increasing the amount of activated carbon prepared from Hazelnut Shells (as adsorbent), the amount of RR2 removal which also increases [50]. The results of this study are consistent with a study by Divriklioglu and Akar [51].

The initial concentration of dye in the solution has a significant effect on the number of effective collisions between the adsorbent surfaces and the adsorbed molecules [52]. The effect of initial dye concentration was evaluated in the range of $100-500 \mathrm{mg} / \mathrm{L}$. The effect of initial dye concentration on the dye removal efficiency showed that overall dye removal efficiency decreased with increasing dye concentration. For example, increase in dye from 100 to $500 \mathrm{mg} / \mathrm{L}$ decreases the decolorization from $94 \%$ to $61.6 \%$ at $90 \mathrm{~min}$.
As the dye concentration increases, the adsorbent vacancy sites decrease for dye adsorption [53].

3.4. Adsorption Isotherms. Adsorption isotherm data are of great importance in adsorption studies in order to optimize the design of the adsorption system. Various isotherm equations such as Langmuir and Freundlich isotherms were used to investigate the RR2 dye adsorption equilibrium on GWAC [56].

Based on Langmuir isotherm, adsorption occurs by monolayer coating at homogeneous sites with a limited number [57]. Furthermore, once dyes molecule occupies a site, no further adsorption can take place at that site. Langmuir isotherms can be plotted at four different linear types. Equations (5)-(8) show the linear form of four types of Langmuir isotherm models [58]:

$$
\begin{gathered}
\text { Type (I): } \frac{C_{e}}{q_{e}}=\frac{C_{e}}{Q_{m}}+\frac{1}{K Q_{m}}, \\
\text { Type (II): } \frac{1}{q_{e}}=\frac{1}{Q_{m}}+\frac{1}{K C_{e} Q_{m}}, \\
\text { Type (III) } q_{e}=Q_{m}-\frac{q_{e}}{K C_{e}}, \\
\text { Type (IV) } \frac{q_{e}}{C_{e}}=K Q_{m}-K q_{e},
\end{gathered}
$$

where $C_{e}(\mathrm{mg} / \mathrm{L})$ is the equilibrium concentration of RR2 dye in the solution, $q_{e}(\mathrm{mg} / \mathrm{g})$ is the adsorption capacity at equilibrium, $Q_{m}(\mathrm{mg} / \mathrm{g})$ is the maximum adsorption capacity, and $K(\mathrm{~L} / \mathrm{mg})$ is the effective dissociation constant that relates to the affinity binding site. The values of $Q_{m}$ and $K$ are obtained from the intercept and the slope of the linear plot of $C_{e} / q_{e}$ against $C_{e}[59]$.

One of the parameters of the Langmuir equation, which determines the type of adsorption process, is the coefficient of separation parameter RL. When $1<\mathrm{RL}$ shows an undesirable adsorption type, $\mathrm{RL}=1$ is a linear adsorption type, 0 $<\mathrm{RL}<1$ is optimal adsorption, and $\mathrm{RL}=0$ is an irreversible adsorption [60]. According to the study of adsorption isotherms, the amount of RL for RR2 adsorption is calculated to be $0<\mathrm{RL}<1$, which indicates that the RR2 is well adsorbed in this work (Eq. (9)).

$$
\mathrm{RL}=\frac{1}{1+\mathrm{KC}}
$$




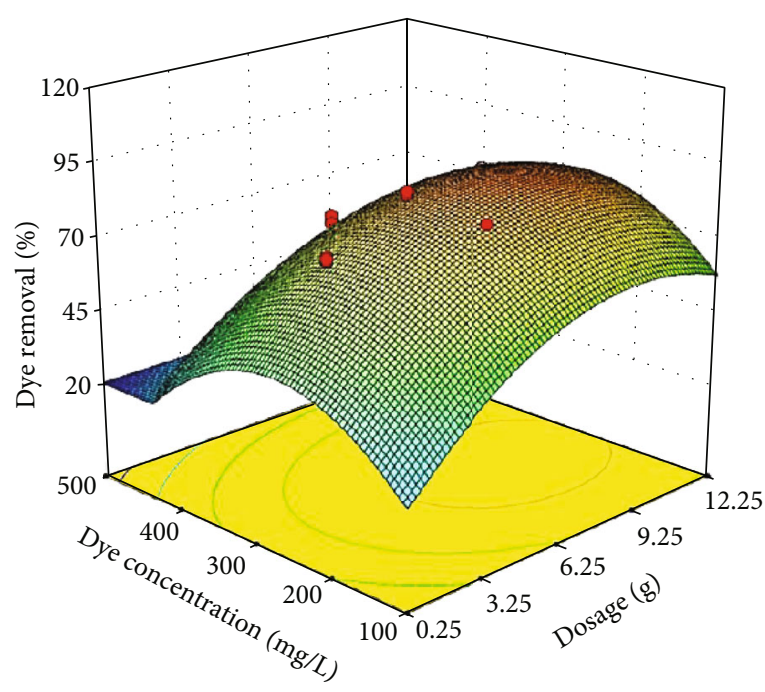

(a)

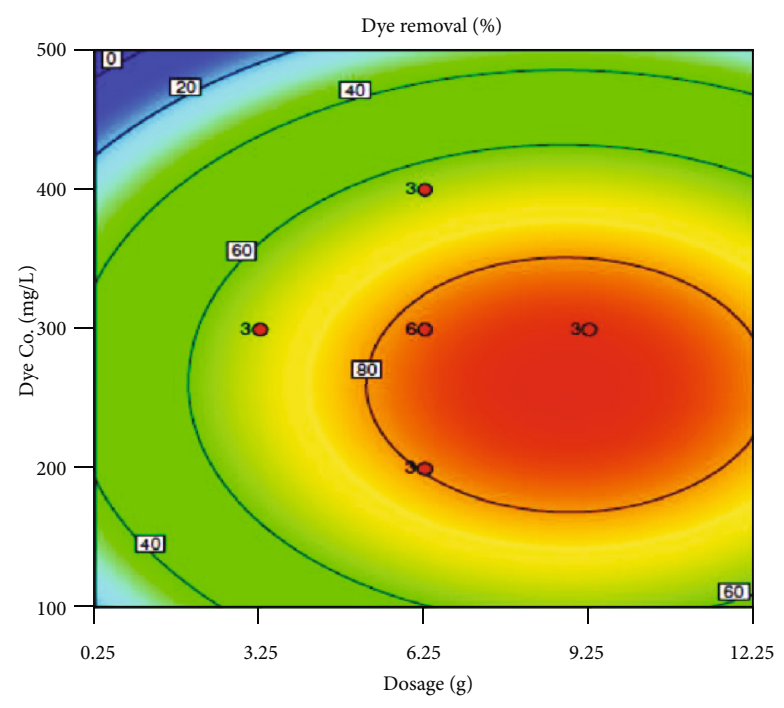

(b)

Figure 5: 3D response surface and 2D contour plots show the effect of dosage and dye concentration on the RR2 removal.

The Freundlich isotherm describes heterogeneous adsorption with different surface energy sites. In this model, the amount of dye adsorption changes with the exponential distribution of sites and adsorption energies. The linear form of the Freundlich isotherm is shown in Eq. (10) [61, 62]:

$$
\ln \mathrm{q}_{e}=\ln k_{f}+\frac{1}{n} \ln c_{e}
$$

where $n$ and $K_{F}$ are Freundlich adsorption isotherm constants, which indicate adsorption intensity and adsorption capacity, respectively. The Freundlich isotherm constants $K_{F}$ and $1 / n$ can be reported based on the plot of $\operatorname{lnq}_{e}$ versus $\operatorname{lnC}_{e}$, which has been presented in Figure 6. If the value of $1 / n<1$, then the adsorption intensity and the type of isotherm are to be required, and the adsorption capacity increases with the appearance of new adsorption sites. Nonetheless, if $1 / n>1$, the adsorption bond weakens, and its adsorption is very challenging that decreases the adsorption capacity [63].

In present work, the equilibrium adsorption data were analyzed using the Langmuir and Freundlich adsorption models. The parameters obtained from Figures 7 and 6 are summarized in Table 5.

Comparison of $R^{2}$ values in Table 5 shows that the experimental data obtained are more consistent with the Langmuir isotherm $\left(R^{2}=0.9674\right)$. The validity of the Langmuir isotherm in RR2 dye adsorption indicates that adsorption occurs on the surface of the GWAC adsorbent monolayer. Therefore, it needs the equal activation energy to adsorption all species.

3.5. Kinetic Study. Kinetics is one of the important characteristics in defining the efficiency of adsorbent. Adsorption kinetics describes the rate of adsorption of solutes, which

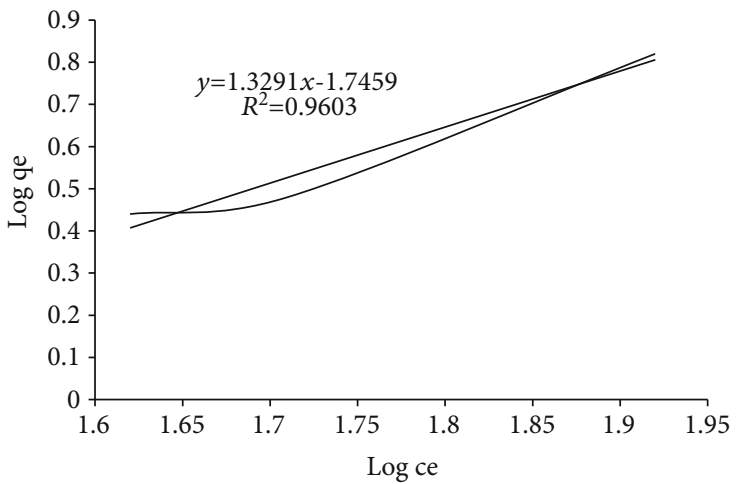

FIGURE 6: Freundlich isotherm for RR2 adsorption on GWAC at $(\mathrm{pH}=7$, contact time $=50 \mathrm{~min}$, dye concentration $=300 \mathrm{mg} / \mathrm{L})$.

in turn depends on the retention time or adsorption reaction. Kinetic parameters can be calculated by analyzing experimental data obtained at different times. Therefore, in this way, some information needed to design and model the adsorption processes that can be obtained [64].

3.5.1. The Pseudofirst-Order Model. The linear form of the pseudofirst-order equation can be represented using the following equation (Eq. (11)):

$$
\log (q e-q t)=\log q e-\frac{K 1}{2.0303 t},
$$

where $q_{e}$ is the amount of dye adsorbed at equilibrium $(\mathrm{mg} / \mathrm{g}), q_{t}$ is the amount of dye adsorbed at any time $t$ $(\mathrm{mg} / \mathrm{g})$, and $K_{1}$ is the first order rate constant $\left(\mathrm{min}^{-1}\right)$. 


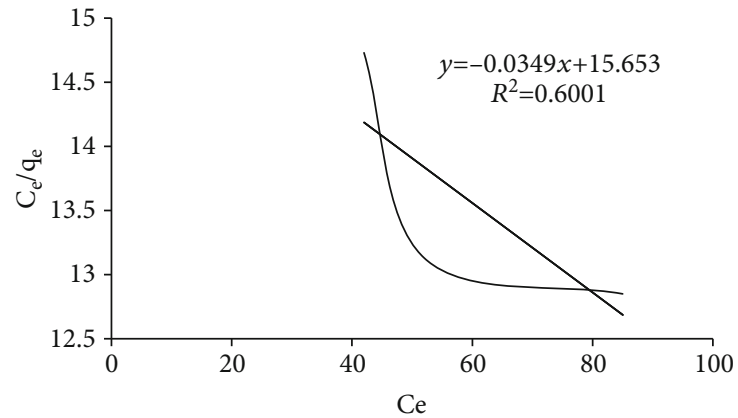

(a)

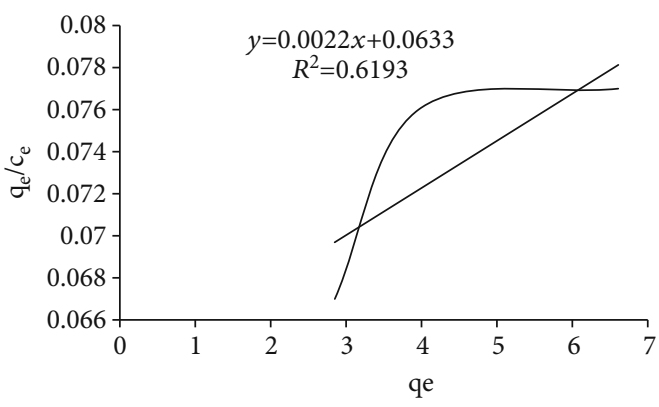

(c)

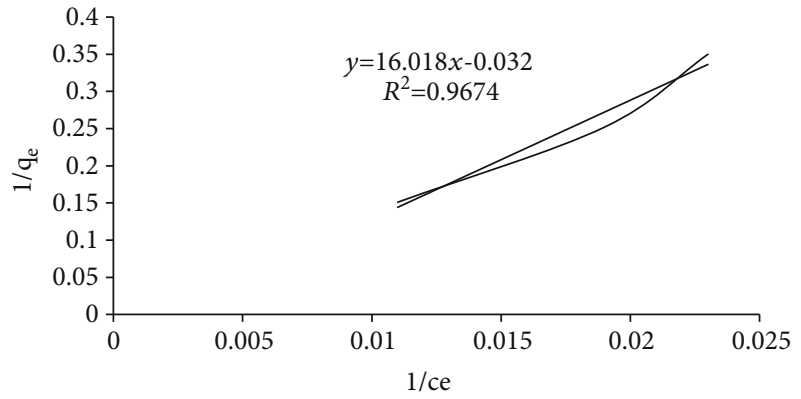

(b)

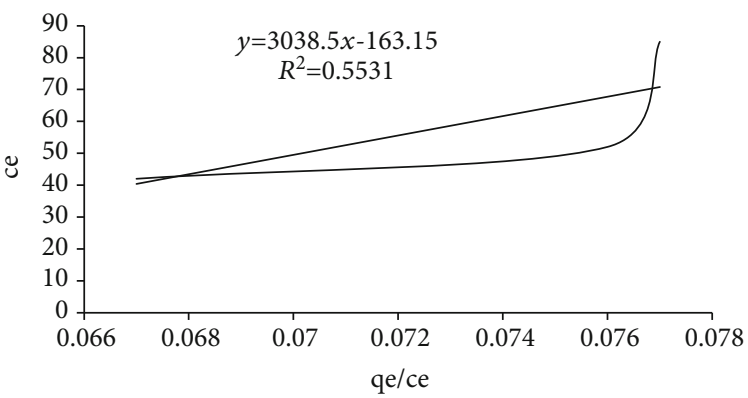

(d)

FIGURE 7: Langmuir isotherm for RR2 adsorption on GWAC (a) type 1 Langmuir, (b) type 2 Langmuir, (c) type 3 Langmuir, and (d) type 4 Langmuir at $(\mathrm{pH}=7$, contact time $=50 \mathrm{~min}$, dye concentration $=300 \mathrm{mg} / \mathrm{L})$.

TABLE 5: Isotherm model parameters and correlation coefficients for RR2 adsorption on GWAC.

\begin{tabular}{lcc}
\hline Isotherm & Parameters & Adsorbent \\
\hline \multirow{2}{*}{ Langmuir 1 } & $R^{2}$ & 0.60 \\
& $Q_{m}(\mathrm{mg} / \mathrm{g})$ & 28.65 \\
& $K_{L 1}\left(\mathrm{~L} / \mathrm{mg}^{\prime}\right)$ & 0.002 \\
& $\mathrm{RL}$ & 0.62 \\
& $R^{2}$ & 0.9674 \\
Langmuir 2 & $Q_{m}(\mathrm{mg} / \mathrm{g})$ & 0.062 \\
& $K_{L 2}(\mathrm{~L} / \mathrm{mg})$ & 504.03 \\
& $\mathrm{RL}$ & 0.000006 \\
& $R^{2}$ & 0.6193 \\
Langmuir 3 & $Q_{m}(\mathrm{mg} / \mathrm{g})$ & 454.54 \\
& $K_{L 3}(\mathrm{~L} / \mathrm{mg})$ & 0.034 \\
& $\mathrm{RL}$ & 0.089 \\
& $R^{2}$ & 0.5531 \\
Langmuir 4 & $Q_{m}(\mathrm{mg} / \mathrm{g})$ & 0.0003 \\
& $K_{L 4}(\mathrm{~L} / \mathrm{mg})$ & 20.44 \\
& $\mathrm{RL}$ & 0.00016 \\
& $R^{2}$ & 0.96 \\
& $1 / n$ & 1.33 \\
& $K_{f}(\mathrm{mg} / \mathrm{g})$ & 55.59 \\
\hline
\end{tabular}

3.5.2. The Pseudosecond-Order Model. The pseudosecondorder model equation was proposed in 1995 by Ho. This equation shows how the pertained rate of adsorption is related to

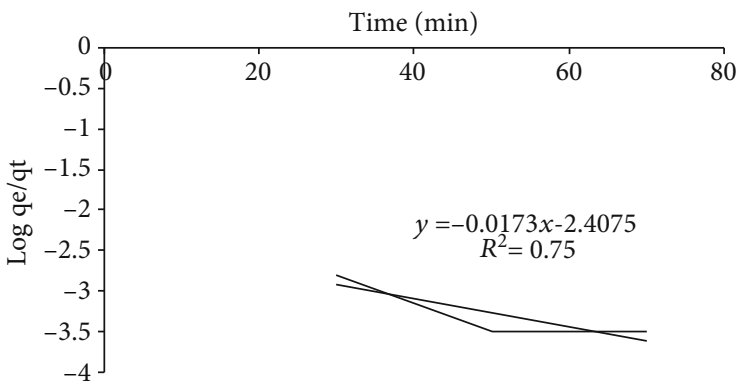

FIgURE 8: The pseudofirst-order kinetic plots for the adsorption of RR2 onto prepared adsorbent.

the equilibrium value [65]. Four types of the pseudosecondorder model were defined as (Eqs. (12)-(15)) [66]:

$$
\begin{gathered}
\text { Type (I): } \frac{t}{q_{t}}=\frac{1}{k_{21} q_{e}^{2}}+\frac{1}{q_{e}} t \\
\text { Type (II): } \frac{1}{q_{t}}=\frac{1}{q_{e}}+\left(\frac{1}{k_{22} q_{e}^{2}}\right) \frac{1}{t},
\end{gathered}
$$

$$
\text { Type (III): } q_{t}=q_{e}-\left(\frac{1}{k_{23} q e}\right) \frac{q t}{t} \text {, }
$$

Type (IV): $\frac{q t}{t}=k_{24} q_{e}^{2}-k_{24} q e q t$, 


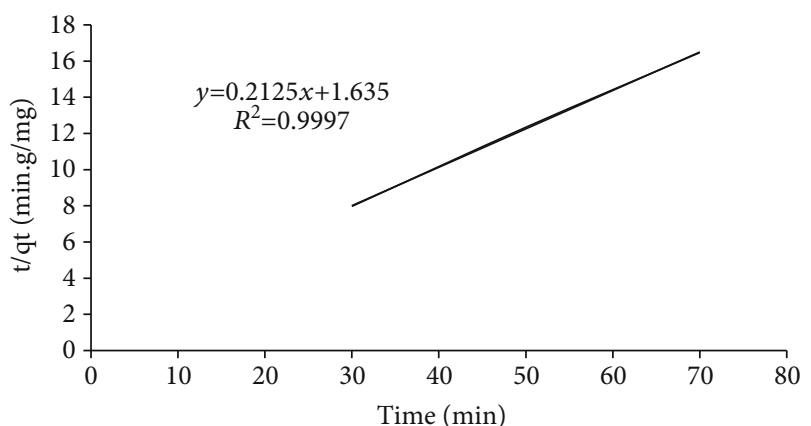

(a)

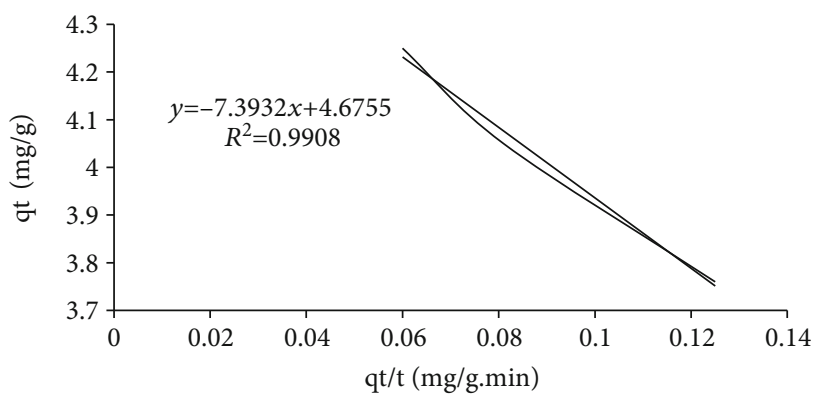

(c)

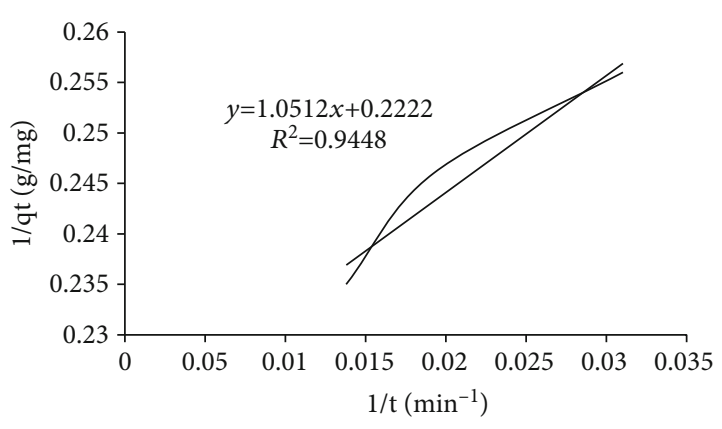

(b)

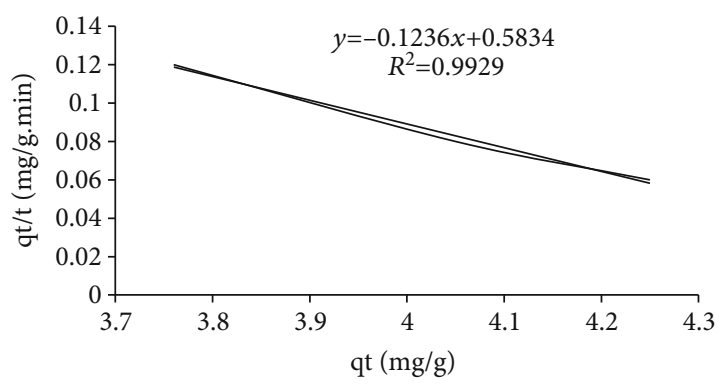

(d)

FIGURE 9: The pseudosecond-order kinetic plots for RR2 adsorption on GWAC (a) type 1: the pseudosecond-order, (b) type 2: the pseudosecond-order, (c) type 3: the pseudosecond-order, and (d) type 4: the pseudosecond-order.

TABLE 6: Kinetic model parameters and correlation coefficients for RR2 adsorption on GWAC.

\begin{tabular}{lcc}
\hline Model & Parameters & Adsorbent \\
\hline \multirow{3}{*}{ Pseudofirst-order } & $R^{2}$ & 0.75 \\
& $Q_{m}(\mathrm{mg} / \mathrm{g})$ & 501.18 \\
& $K_{1}(1 / \mathrm{min})$ & 0.03 \\
Pseudosecond-order (type I) & $R^{2}$ & 0.9997 \\
& $Q_{m}(\mathrm{mg} / \mathrm{g})$ & 4.70 \\
& $K_{2}(\mathrm{~g} / \mathrm{min} \cdot \mathrm{mg})$ & 0.02 \\
Pseudosecond-order (type II) & $R^{2}$ & 0.9448 \\
& $Q_{m}(\mathrm{mg} / \mathrm{g})$ & 0.95 \\
& $K_{2}(\mathrm{~g} / \mathrm{min} \cdot \mathrm{mg})$ & 5.05 \\
Pseudosecond-order (type III) & $R^{2}$ & 0.9908 \\
& $Q_{m}(\mathrm{mg} / \mathrm{g})$ & 0.13 \\
& $K_{2}(\mathrm{~g} / \mathrm{min} \cdot \mathrm{mg})$ & 21.73 \\
& $R^{2}$ & 0.9929 \\
Pseudosecond-order (type IV) & $Q_{m}(\mathrm{mg} / \mathrm{g})$ & 8.33 \\
& $K_{2}(\mathrm{~g} / \mathrm{min} \cdot \mathrm{mg})$ & 0.02 \\
\hline
\end{tabular}

where $K_{2}$ is the pseudosecond-order rate constant (g.mg$\left.{ }^{1} \cdot \mathrm{min}^{-1}\right), q_{e}$ is the amount of dye adsorbed on the adsorbent at equilibrium $(\mathrm{mg} / \mathrm{g})$, and $q_{t}$ is the amount of dye adsorbed on the adsorbent at any time $t(\mathrm{mg} / \mathrm{g})$ [67].

Based on Figures 8 and 9, the experimental results at different times show that the data follows a pseudosecondorder kinetic model. The kinetic parameters for the
TABLE 7: Thermodynamic parameters for the adsorption of RR2 on GWAC at $24 \pm 2^{\circ} \mathrm{C}$.

\begin{tabular}{lcc}
\hline RR2 conc. $(\mathrm{mg} / \mathrm{L})$ & $K_{\mathrm{o}} / \mathrm{L} \mathrm{g}^{-1}$ & $\Delta G^{\circ}(\mathrm{kJ} / \mathrm{Kmol})$ \\
\hline 100 & 39 & -9.03 \\
200 & 10.11 & -5.70 \\
300 & 9 & -5.40 \\
400 & 2.27 & -2 \\
500 & 1.79 & -1.43 \\
\hline
\end{tabular}

pseudofirst-order and pseudosecond-order models are summarized in Table 6.

3.6. Adsorption Thermodynamics. To understand the properties and mechanisms of adsorption, the thermodynamic parameters such as standard enthalpy change) $\Delta H^{\circ}$ (, Gibbs free energy change) $\Delta G^{\circ}$ (, and standard entropy change) $\Delta$ $S^{\circ}$ (were measured using the following equations (Eqs. (16)-(19)) [11, 68, 69].

$$
\begin{gathered}
\Delta G^{\circ}=-\mathrm{RT} \mathrm{Rk}_{\mathrm{o}}, \\
k_{\mathrm{o}}=\frac{q e}{c e}, \\
\Delta G^{\circ}=\Delta H^{\circ}-T \Delta S^{\circ}, \\
\operatorname{lnk}_{\mathrm{o}}=\frac{\Delta S^{\circ}}{R}=\frac{\Delta H^{\circ}}{\mathrm{RT}},
\end{gathered}
$$

where $R$ is the universal gas constant $\left(8.314 \mathrm{~J} \mathrm{~mol}^{-1} \mathrm{~K}^{-1}\right)$, $K$ is the equilibrium constant, and $T$ is the temperature $(K)$. 
$\Delta H^{\circ}$ and $\Delta S^{\circ}$ can be obtained from the slope and intercept of the linear plots of $\ln K_{0}$ vs. $1 / T$, respectively. According to the results (Table 7), the values of $\Delta G^{\circ}$ in all concentrations tested at $24 \pm 2^{\circ} \mathrm{C}$ were negative. Therefore, it can be concluded that the adsorption of RR2 on GWAC is spontaneous and thermodynamically desirable. On the other hand, the more negative the Gibbs standard energy is, the higher the adsorption driving force and consequently the higher the adsorption capacity [56].

\section{Conclusion}

In this study, the removal of RR2 dye from aqueous solution using grape wood-based activated carbon was investigated. Parametric studies, optimization, thermodynamics, adsorption isotherm and kinetic studies were done and following conclusions were obtained:

(i) Using the Design-Expert software, the optimum parameter conditions of $100 \mathrm{mg} / \mathrm{L}$ initial RR2 concentration, $90 \mathrm{~min}$ contact time, $12.25 \mathrm{~g} / \mathrm{L}$ adsorbent dose, and $\mathrm{pH}$ of 3 were determined to yield a maximum RR2 removal of $96.83 \%$

(ii) The percentage removal of RR2 increases with increasing adsorbent dose and contact time

(iii) The percent (\%) of RR2 removal increases with decreasing $\mathrm{pH}$ and initial dye concentration

(iv) The Langmuir isotherm of type (II) best described the equilibrium data with $R^{2}=0.96$, which indicates the monolayer adsorption model takes place between RR2 dye and GWAC

(v) The pseudosecond-order kinetic model of type (I) best describes the kinetics of the GWAC adsorption system due to its high $R^{2}=0.99$

(vi) Conclusively, grape wood-based activated carbon is an effective and low-cost adsorbent in the removal of RR2 dye from aqueous solution, where process parameters such as solution $\mathrm{pH}$, initial dye concentration, contact time, and adsorbent dose significantly affect the percentage removal of RR2

\section{Abbreviations}

$b$ : Constant related to the affinity of the binding sites [L/ $\mathrm{mg}$ ]

$C_{0}: \quad$ Liquid-phase concentrations of dye at initial $[\mathrm{mg} / \mathrm{L}]$

$C_{e}: \quad$ Liquid-phase concentrations of dye at equilibrium $[\mathrm{mg} / \mathrm{L}]$

$C_{t}: \quad$ Liquid-phase concentrations of dye at any time [mg/ L]

$K_{L}: \quad$ Langmuir constant [L/mg]

$K_{F}: \quad$ Freundlich constant $[\mathrm{mg} / \mathrm{g}]$

$K_{1}$ : Pseudofirst-order rate constant $\left[\mathrm{min}^{-1}\right]$

$K_{2}: \quad$ Pseudosecond-order rate constant $[\mathrm{g} / \mathrm{mg} \mathrm{min}]$

$n: \quad$ Dimensionless exponent of Freundlich equation

$q_{t}: \quad$ Amount of biosorption at time $t[\mathrm{mg} / \mathrm{g}]$ $q_{e}: \quad$ Amount of adsorbed dye per unit mass of sorbent $[\mathrm{mg} / \mathrm{g}]$

$q_{m}: \quad$ Maximum amount of the adsorbed dye per unit mass of sorbent $[\mathrm{mg} / \mathrm{g}]$

$K_{o}: \quad$ The standard thermodynamic equilibrium constant $L g^{-1}$

$\Delta G^{\circ}:$ Standard free energy $[\mathrm{kJ} / \mathrm{Kmol}]$

$\Delta S^{\circ}:$ Entropy $[\mathrm{J} / \mathrm{Kmol}]$

$\Delta H^{\circ}$ : Enthalpy $[\mathrm{kJ} / \mathrm{Kmol}]$

$\mathrm{R}_{\mathrm{L}}$ : Dimensionless constant separation factor

AC: Activated carbon

RSM: Response surface methodology

RR2: Reactive Red 2.

\section{Data Availability}

The [data type] data used to support the findings of this study are included within the article.

\section{Conflicts of Interest}

The authors declare that they have no conflicts of interest.

\section{Acknowledgments}

The authors would like to thank the Research Council of Kermanshah University of Medical Sciences for its financial support of this project (Project No. 94037).

\section{References}

[1] M. R. R. Kooh, L. B. L. Lim, L. H. Lim, and M. K. Dahri, “Separation of toxic rhodamine B from aqueous solution using an efficient low-cost material, Azolla pinnata, by adsorption method," Environmental monitoring and assessment, vol. 188, no. 2, p. 108, 2016.

[2] Ö. Gök, A. S. Özcan, and A. Özcan, “Adsorption behavior of a textile dye of reactive blue 19 from aqueous solutions onto modified bentonite," Applied Surface Science, vol. 256, no. 17, pp. 5439-5443, 2010.

[3] Y. Safa and H. N. Bhatti, "Adsorptive removal of direct textile dyes by low cost agricultural waste: application of factorial design analysis," Chemical Engineering Journal, vol. 167, no. 1, pp. 35-41, 2011.

[4] B. R. Vergis, R. H. Krishna, N. Kottamet, B. M. Nagabhushana, R. Sharath, and B. Darukaprasad, "Removal of malachite green from aqueous solution by magnetic $\mathrm{CuFe}_{2} \mathrm{O}_{4}$ nano-adsorbent synthesized by one pot solution combustion method," Journal of Nanostructure in Chemistry, vol. 8, no. 1, pp. 1-12, 2018.

[5] H. Khoshsang, A. Ghafarinejad, H. Kazemi, Y. Wang, and H. Arandiyan, "One-pot synthesis of S-doped $\mathrm{Fe}_{2} \mathrm{O}_{3} / \mathrm{C}$ magnetic nanocomposite as an adsorbent for anionic dye removal: equilibrium and kinetic studies," Journal of Nanostructure in Chemistry, vol. 8, no. 1, pp. 23-32, 2018.

[6] A. Almasi, S. A. Mousavi, A. Hesari, and H. Janjani, "Walnut shell as a natural adsorbent for the removal of reactive red 2 form aqueous solution," Journal of Applied and Basic Sciences, vol. 10, pp. 551-556, 2016.

[7] V. Gupta, "Application of low-cost adsorbents for dye removal - a review," Journal of Environmental Management, vol. 90, no. 8, pp. 2313-2342, 2009. 
[8] D. Nayeri and S. A. Mousavi, "Dye removal from water and wastewater by nanosized metal oxides-modified activated carbon: a review on recent researches," Journal of Environmental Health Science and Engineering, vol. 18, no. 2, pp. 1671-1689, 2020.

[9] S. A. Mousavi and S. Nazari, “Applying response surface methodology to optimize the Fenton oxidation process in the removal of Reactive Red 2," Polish Journal of Environmental Studies, vol. 26, no. 2, 2017.

[10] M. El Haddad, R. Mamouni, N. Saffaj, and S. Lazarb, "Evaluation of performance of animal bone meal as a new low cost adsorbent for the removal of a cationic dye rhodamine B from aqueous solutions," Journal of Saudi Chemical Society, vol. 20, pp. S53-S59, 2016.

[11] A. Torabinejad, N. Nasirizadeh, M. E. Yazdanshenaset, and H. A. Tayebi, "Synthesis of conductive polymer-coated mesoporous MCM-41 for textile dye removal from aqueous media," Journal of Nanostructure in Chemistry, vol. 7, no. 3, pp. 217229, 2017.

[12] H. Patel and R. Vashi, "Removal of Congo red dye from its aqueous solution using natural coagulants," Journal of Saudi Chemical Society, vol. 16, no. 2, pp. 131-136, 2012.

[13] G. Moussavi and M. Mahmoudi, "Degradation and biodegradability improvement of the reactive red 198 azo dye using catalytic ozonation with $\mathrm{MgO}$ nanocrystals," Chemical Engineering Journal, vol. 152, no. 1, pp. 1-7, 2009.

[14] G. F. Pereira, A. El-Ghenymy, A. Thiam et al., "Effective removal of Orange-G azo dye from water by electro-Fenton and photoelectro-Fenton processes using a boron-doped diamond anode," Separation and Purification Technology, vol. 160, pp. 145-151, 2016.

[15] V. Bharti, K. Vikrant, M. Goswami et al., "Biodegradation of methylene blue dye in a batch and continuous mode using biochar as packing media," Environmental Research, vol. 171, pp. 356-364, 2019.

[16] I. Ali, O. M. L. Alharbi, Z. A. Alothman, and A. Y. Badjah, "Kinetics, thermodynamics, and modeling of amido black dye photodegradation in water using $\mathrm{co} / \mathrm{TiO}_{2}$ nanoparticles," Photochemistry and Photobiology, vol. 94, no. 5, pp. 935-941, 2018.

[17] J. Shen, Y. Wu, B. Zhang, and F. Li, "Adsorption of rhodamine $\mathrm{B}$ dye by biomimetic mesoporous $\mathrm{SiO}_{2}$ nanosheets," Clean Technologies and Environmental Policy, vol. 17, no. 8, pp. 2289-2298, 2015.

[18] M. H. Saghi, A. Allahabadi, S. Rahmani, T. Vazeiri, and R. Hekmatshoar, "Removal of reactive orange 3 dye from aqueous solution by biosorption technology," Scientific Information Database, vol. 19, no. 64, pp. 127-135, 2012.

[19] V. Garg, R. Kumar, and R. Gupta, "Removal of malachite green dye from aqueous solution by adsorption using agro- industry waste: a case study of _Prosopis cineraria_" Dyes and Pigments, vol. 62, no. 1, pp. 1-10, 2004.

[20] D. L. Postai, C. A. Demarchi, F. Zanatta, D. C. C. Melo, and C. A. Rodrigues, "Adsorption of rhodamine B and methylene blue dyes using waste of seeds of _Aleurites Moluccana_, a low cost adsorbent," Alexandria Engineering Journal, vol. 55, no. 2, pp. 1713-1723, 2016.

[21] W. Xiao, Z. N. Garba, S. Sun et al., "Preparation and evaluation of an effective activated carbon from white sugar for the adsorption of rhodamine B dye," Journal of Cleaner Production, vol. 253, p. 119989, 2020.
[22] G. Vijayakumar, R. Tamilarasan, and M. Dharmendirakumar, "Adsorption, kinetic, equilibrium and thermodynamic studies on the removal of basic dye rhodamine-B from aqueous solution by the use of natural adsorbent perlite," Journal of Materials and Environmental Science, vol. 3, no. 1, pp. 157-170, 2012.

[23] W. Wafwoyo, C. W. Seo, and W. E. Marshall, "Utilization of peanut shells as adsorbents for selected metals," Journal of Chemical Technology and Biotechnology: International Research in Process, Environmental and Clean Technology, vol. 74, no. 11, pp. 1117-1121, 1999.

[24] M. Soleimani and T. Kaghazchi, "Activated hard shell of apricot stones: a promising adsorbent in gold recovery," Chinese Journal of Chemical Engineering, vol. 16, no. 1, pp. 112-118, 2008.

[25] I. Ozdemir, M. Şahin, R. Orhan, and M. Erdem, "Preparation and characterization of activated carbon from grape stalk by zinc chloride activation," Fuel Processing Technology, vol. 125, pp. 200-206, 2014.

[26] K. Nyazi, A. Yaacoubi, A. Baçaoui et al., "Preparation and characterization of new adsorbent materials from the olive wastes," Journal de Physique IV, vol. 123, pp. 121-124, 2005.

[27] M. G. Lussier, J. C. Shull, and D. J. Miller, "Activated carbon from cherry stones,” Carbon, vol. 32, no. 8, pp. 1493-1498, 1994.

[28] A. Inyinbor, F. Adekola, and G. Olatunji, "Liquid phase adsorptions of rhodamine $\mathrm{B}$ dye onto raw and chitosan supported mesoporous adsorbents: isotherms and kinetics studies," Applied Water Science, vol. 7, no. 5, pp. 2297-2307, 2017.

[29] A. Inyinbor, F. Adekola, and G. A. Olatunji, "Kinetics, isotherms and thermodynamic modeling of liquid phase adsorption of Rhodamine B dye onto _Raphia hookerie_ fruit epicarp," Water Resources and Industry, vol. 15, pp. 14-27, 2016.

[30] X. Sun, X. Wei, J. Zhang et al., "Biomass estimation and physicochemical characterization of winter vine prunings in the Chinese and global grape and wine industries," Waste Management, vol. 104, pp. 119-129, 2020.

[31] C. C. Lin, Y. S. Lin, and J. M. Ho, "Adsorption of reactive red 2 from aqueous solutions using $\mathrm{Fe}_{3} \mathrm{O}_{4}$ nanoparticles prepared by co-precipitation in a rotating packed bed," Journal of Alloys and Compounds, vol. 666, pp. 153-158, 2016.

[32] A. Witek-Krowiak, K. Chojnackab, D. Podstawczyka, A. Dawieca, and K. Pokomeda, "Application of response surface methodology and artificial neural network methods in modelling and optimization of biosorption process," Bioresource Technology, vol. 160, pp. 150-160, 2014.

[33] S. A. Mousavi and S. Ibrahim, "Application of response surface methodology (RSM) for analyzing and modeling of nitrification process using sequencing batch reactors," Desalination and Water Treatment, vol. 57, no. 13, pp. 5730-5739, 2016.

[34] S. Sharifi, R. Nabizadeh, B. Akbarpour et al., "Modeling and optimizing parameters affecting hexavalent chromium adsorption from aqueous solutions using $\mathrm{Ti}-\mathrm{XAD}_{7}$ nanocomposite: RSM-CCD approach, kinetic, and isotherm studies," Journal of Environmental Health Science and Engineering, vol. 17, no. 2, pp. 873-888, 2019.

[35] S. J. Allen, G. Mckay, and J. F. Porter, "Adsorption isotherm models for basic dye adsorption by peat in single and binary component systems," Journal of Colloid and Interface Science, vol. 280, no. 2, pp. 322-333, 2004.

[36] A. Seidmohammadi, G. Asgari, M. Leili, A. Dargahi, and A. Mobarakian, "Effectiveness of quercus branti activated 
carbon in removal of methylene blue from aqueous solutions," Archives of Hygiene Sciences, vol. 4, no. 4, pp. 217-225, 2015.

[37] S. A. Mousavi, M. Mehralian, M. Khashij, and S. Parvaneh, "Methylene blue removal from aqueous solutions by activated carbon prepared from N. microphyllum (AC-NM): RSM analysis, isotherms and kinetic studies," Global NEST Journal, vol. 19, no. 4, pp. 697-705, 2019.

[38] E. Rafiee, E. Noori, A. A. Zinatizadeh, and H. Zangeneh, "Surfactant effect on photocatalytic activity of $\mathrm{Ag}-\mathrm{TiO}_{2} / \mathrm{PW}$ nanocomposite in DR16 degradation: Characterization of nanocomposite and RSM process optimization," Materials Science in Semiconductor Processing, vol. 83, pp. 115-124, 2018.

[39] M. Y. Badi, A. Esrafili, H. Pasalari, R. R. Kalantary, E. Ahmadi, and M. Gholami, "Degradation of dimethyl phthalate using persulfate activated by UV and ferrous ions: optimizing operational parameters mechanism and pathway," Journal of Environmental Health Science and Engineering, vol. 17, no. 2, pp. 685-700, 2019.

[40] A. Almasi, Z. Rostamkhani, and S. A. Mousavi, "Adsorption of reactive red 2 using activated carbon prepared from walnut shell: batch and fixed bed studies," Desalination and Water Treatment, vol. 79, pp. 356-367, 2017.

[41] X. B. Zhang, W. Y. Dong, F. Y. Sun, W. Yang, and J. Dong, "Degradation efficiency and mechanism of azo dye RR2 by a novel ozone aerated internal micro-electrolysis filter," Journal of hazardous materials, vol. 276, pp. 77-87, 2014.

[42] S. Nirmaladevi and N. Palanisamy, "A comparative study of the removal of cationic and anionic dye from aqueous solutions using biochar as an adsorbent," Desalination and Water Treatment, vol. 175, pp. 282-292, 2020.

[43] S. Senthilkumaar, P. Kalaamani, K. Porkodi, P. R. Varadarajan, and C. V. Subburaam, "Adsorption of dissolved reactive red dye from aqueous phase onto activated carbon prepared from agricultural waste," Bioresource Technology, vol. 97, no. 14, pp. 1618-1625, 2006.

[44] Z. Aksu and G. Dönmez, "A comparative study on the biosorption characteristics of some yeasts for Remazol blue reactive dye," Chemosphere, vol. 50, no. 8, pp. 1075-1083, 2003.

[45] T. Vidhyadevi, A. Murugesan, S. S. Kalaivani et al., "Optimization of the process parameters for the removal of reactive yellow dye by the low cost Setaria verticillata carbon using response surface methodology: thermodynamic, kinetic, and equilibrium studies," Environmental Progress and Sustainable Energy, vol. 33, no. 3, pp. 855-865, 2014.

[46] L. Ai, C. Zhang, F. Liao et al., "Removal of methylene blue from aqueous solution with magnetite loaded multi- wall carbon nanotube: kinetic, isotherm and mechanism analysis," Journal of Hazardous Materials, vol. 198, pp. 282-290, 2011.

[47] E. Bazrafshan, M. Ahmadabadi, and A. H. Mahvi, "Reactive Red-120 removal by activated carbon obtained from cumin herb wastes," Fresenius Environmental Bulletin, vol. 22, no. 2a, pp. 584-590, 2013.

[48] O. A. Oyetade, V. O. Nyamori, B. S. Martincigh, and S. B. Jonnalagadda, "Effectiveness of carbon nanotube-cobalt ferrite nanocomposites for the adsorption of rhodamine B from aqueous solutions," RSC Advances, vol. 5, no. 29, pp. 2272422739, 2015.

[49] D. J. Naghan, A. Azari, N. Mirzaei et al., "Parameters effecting on photocatalytic degradation of the phenol from aqueous solutions in the presence of $\mathrm{ZnO}$ nanocatalyst under irradiation of UV-C light," Bulgarian Chemical Communications, vol. 47 , pp. 14-18, 2015.
[50] A. N. Al-Sharify, Z. H. Athab, and A. F. Halbus, "Adsorption of reactive red 2 dye onto activated carbon prepared from hazelnut shells," Iraqi National Journal of chemistry, vol. 51, no. 51, 2013.

[51] T. Akar and M. Divriklioglu, "Biosorption applications of modified fungal biomass for decolorization of reactive red 2 contaminated solutions: batch and dynamic flow mode studies," Bioresource Technology, vol. 101, no. 19, pp. 7271-7277, 2010.

[52] M. Rajabi, K. Mahanpoor, and O. Moradi, "Preparation of PMMA/GO and PMMA/GO- $\mathrm{Fe}_{3} \mathrm{O}_{4}$ nanocomposites for malachite green dye adsorption: kinetic and thermodynamic studies," Composites Part B: Engineering, vol. 167, pp. 544-555, 2019.

[53] S. Arivoli and M. Henkuzhali, "Kinetic, mechanistic, thermodynamic and equilibrium studies on the adsorption of rhodamine B by acid activated low cost carbon," Journal of Chemistry, vol. 5, no. 2, 200 pages, 2008.

[54] R. Sahadevan, D. K. Mahendradas, V. Shanmugasundaram, K. Shanmugam, and M. Velan, "Sorption kinetics and equilibrium analysis for the removal of Reactive Red 2 and Reactive Blue 81 dyes from synthetic effluents using dried soya bean meal," International journal of chemical reactor engineering, vol. 7, no. 1, 2009.

[55] M. Kaur and M. Datta, "Adsorption behaviour of reactive red 2 (RR2) textile dye onto clays: equilibrium and kinetic studies," European Chemical Bulletin, vol. 3, no. 8, pp. 838-849, 2014.

[56] O. Moradi and K. Zare, "Adsorption of Pb (II), cd (II) and cu (II) ions in aqueous solution on SWCNTs and SWCNTCOOH surfaces: kinetics studies," Fullerenes, Nanotubes, and Carbon Nanostructures, vol. 19, no. 7, pp. 628-652, 2011.

[57] O. Moradi, M. Aghaie, K. Zare, M. Monajjemi, and H. Aghaie, "The study of adsorption characteristics $\mathrm{Cu}^{2+}$ and $\mathrm{Pb}^{2+}$ ions onto PHEMA and P(MMA-HEMA) surfaces from aqueous single solution," Journal of Hazardous Materials, vol. 170, no. 2-3, pp. 673-679, 2009.

[58] M. Yari, M. Norouzi, A. H. Mahvi, M. Rajabi, A. Yari, and O. Moradi, "Removal of $\mathrm{Pb}$ (II) ion from aqueous solution by graphene oxide and functionalized graphene oxide-thiol: effect of cysteamine concentration on the bonding constant," Desalination and Water Treatment, vol. 57, no. 24, pp. 11195-11210, 2016.

[59] Z. Cheng, L. Zhang, X. Guo, X. Jiang, and R. Liu, "Removal of Lissamine rhodamine $B$ and acid orange 10 from aqueous solution using activated carbon/surfactant: process optimization, kinetics and equilibrium," Journal of the Taiwan Institute of Chemical Engineers, vol. 47, pp. 149-159, 2015.

[60] S. M. Al-Rashed and A. A. Al-Gaid, "Kinetic and thermodynamic studies on the adsorption behavior of rhodamine $\mathrm{B}$ dye on Duolite C-20 resin," Journal of Saudi Chemical Society, vol. 16, no. 2, pp. 209-215, 2012.

[61] M. S. Khalili, K. Zare, O. Moradi, and M. Sillanpää, "Preparation and characterization of MWCNT-COOH-cellulose$\mathrm{MgO}$ NP nanocomposite as adsorbent for removal of methylene blue from aqueous solutions: isotherm, thermodynamic and kinetic studies," Journal of Nanostructure in Chemistry, vol. 8, no. 1, pp. 103-121, 2018.

[62] A. Azari, A. A. Babaie, R. Rezaei-Kalantary, A. Esrafili, M. Moazzen, and B. Kakavandi, "Nitrate removal from aqueous solution by carbon nanotubes magnetized with nano zero-valent iron," Journal of Mazandaran University of Medical Sciences, vol. 23, no. 2, pp. 15-27, 2014. 
[63] P. Kahrizi, F. S. Mohseni-Shahri, and F. Moeinpour, "Adsorptive removal of cadmium from aqueous solutions using $\mathrm{NiFe}_{2} \mathrm{O}_{4}$ /hydroxyapatite/graphene quantum dots as a novel nano-adsorbent," Journal of Nanostructure in Chemistry, vol. 8, no. 4, pp. 441-452, 2018.

[64] F. Nekouei, S. Nekouei, I. Tyagi, and V. K. Gupta, "Kinetic, thermodynamic and isotherm studies for acid blue 129 removal from liquids using copper oxide nanoparticlemodified activated carbon as a novel adsorbent," Journal of Molecular Liquids, vol. 201, pp. 124-133, 2015.

[65] M. Rajabi, K. Mahanpoor, and O. Moradi, "Thermodynamic and kinetic studies of crystal violet dye adsorption with poly (methyl methacrylate)-graphene oxide and poly (methyl methacrylate)-graphene oxide-zinc oxide nanocomposites," Journal of Applied Polymer Science, vol. 136, no. 22, p. 47495, 2019.

[66] M. Yari, M. Rajabi, O. Moradi et al., "Kinetics of the adsorption of $\mathrm{Pb}(\mathrm{II})$ ions from aqueous solutions by graphene oxide and thiol functionalized graphene oxide," Journal of Molecular Liquids, vol. 209, pp. 50-57, 2015.

[67] H. Kaur and R. Kaur, "Removal of rhodamine-B dye from aqueous solution onto pigeon dropping: adsorption, kinetic, equilibrium and thermodynamic studies," Journal of Materials and Environmental Science, vol. 5, no. 6, pp. 1830-1838, 2014.

[68] O. Moradi, K. Zare, M. Monajjemi, M. Yari, and H. Aghaie, "The studies of equilibrium and thermodynamic adsorption of $\mathrm{Pb}$ (II), cd (II) and cu (II) ions from aqueous solution onto SWCNTs and SWCNT-COOH surfaces," Fullerenes, Nanotubes, and Carbon Nanostructures, vol. 18, no. 3, pp. 285302, 2010.

[69] A. Azari, M. Salari, M. H. Dehghani et al., "Efficiency of magnitized graphene oxide nanoparticles in removal of 2, 4dichlorophenol from aqueous solution," Journal of Mazandaran University of Medical Sciences, vol. 26, no. 144, pp. 265-281, 2017. 